\title{
Cerebellar atrophy on top of motor neuron compromise as indicator of late-onset GM2 gangliosidosis
}

\author{
Hans Thomas Hölzer ${ }^{1}$. Felix Boschann ${ }^{2}$. Julia B. Hennermann ${ }^{3}$. Gabriele Hahn ${ }^{4}$. Andreas Hermann ${ }^{5}$. \\ Maja von der Hagen ${ }^{1} \cdot$ Victoria Tüngler $^{1,6}$ (])
}

Received: 6 February 2021 / Revised: 21 February 2021 / Accepted: 23 February 2021 / Published online: 9 March 2021

(c) The Author(s) 2021

Dear Sirs,

An 18-year-old-male of healthy non-consanguineous parents presented with slowly progressive muscle weakness. The onset of his clinical symptoms began at the age of 13 years with fatigue and muscle pain. 1 year later he complained about increasing walking difficulties. On physical examination the patient exhibited cachexia, dysarthria, scoliosis, generalized muscular atrophy, bilateral symmetric hyperreflexia, a mild ataxic gait as well as subtle bilateral action tremor. Electromyography revealed signs of diffuse denervation reminiscent of lower motor neuron degeneration or anterior horn disease. Magnetic resonance imaging (MRI) of the brain at the age of 16 years showed moderate diffuse cerebellar atrophy without supratentorial cerebral atrophy

Victoria Tüngler

victoria.tuengler@uniklinikum-dresden.de

1 Abteilung Neuropädiatrie, Medizinische Fakultät Carl Gustav Carus, Technische Universität Dresden, Dresden, Germany

2 Institute of Medical Genetics and Human Genetics, Charité - Universitätsmedizin Berlin, corporate member of Freie Universität Berlin and Humboldt-Universität zu Berlin, Berlin, Germany

3 Department of Pediatric and Adolescent Medicine, University Medical Centre Mainz, Mainz, Germany

4 Bereich Kinderradiologie, Institut und Poliklinik für Diagnostische und Interventionelle Radiologie, Medizinische Fakultät Carl Gustav Carus, Technische Universität Dresden, Dresden, Germany

5 Translational Neurodegeneration Section "Albrecht-Kossel", Department of Neurology, University Medical Centre Rostock, University of Rostock, Rostock, Germany

6 UniversitätsCentrum für Seltene Erkrankungen, Medizinische Fakultät Carl Gustav Carus, Technische Universität Dresden, Dresden, Germany
(Fig. 1). Serum creatine kinase (CK) levels were repeatedly elevated (max. 2.5-fold).

The patient was included in TRANSLATE-NAMSE, an innovation project of the German Federal Joint Committee to improve the care of patients with rare diseases. The study was conducted with approval by the Ethics Committee of the Technische Universität Dresden. Following written informed consent, genomic DNA from the index patient was enriched with a SureSelect Human All Exon Kit V6 (Agilent technologies, Santa Clara, California) for subsequent exome sequencing on a HiSeq2500 (Illumina, San Diego, California). Reads were aligned to the GRCh37/hg19 build of the human reference genome. Variants were filtered by minor allele frequency, mode of inheritance and predicted functional impact using the VarFish platform [1]. For further prioritization of variants, we used the following HPO terms [2]: muscle weakness-HP:0001324, dysarthriaHP:0001260, hyperreflexia-HP:0001347, elevated serum CK-HP:0003236, fasciculations-HP:0002380 and skeletal muscle atrophy-HP:0003202. Detected variants were classified according to the guidelines of the American College of Medical Genetics [3]. Co-segregation was performed using Sanger Sequencing. Variant analysis identified two pathogenic variants in HEXA (NM_000520.6): c.508C > T, p.(Arg 170Trp) and c.805G $>$ A, p.(Gly269Ser) in compound heterozygous state, leading to the rare diagnosis of late-onset Tay-Sachs disease (LOTS; Fig. 1).

Fluorometric measurements of the lysosome isoenzyme HexA and HexB activity in leucocytes using 4-methylumbelliferyl derivatives confirmed a severely reduced HexA activity of $2 \%$ ( $0.03 \mathrm{nmol} / 1 / \mathrm{min}$, reference $0.96-1.78)$, while HexB activity was within normal range, consistent with LOTS.

Prior to establishment of the patient's diagnosis, a neuropsychological assessment at the age of 16/17 years, using subtests of the German adaptations of either the Wechsler Adult Intelligence Scale-Revised (HAWIE-R) and the 
Fig. 1 Genetic and clinical findings. a Pedigree and electropherograms showing the mutations in the HEXA gene. The affected patient inherited the two pathogenic variants c. $508 \mathrm{C}>\mathrm{T}$ (paternal) and c. $805 \mathrm{G}>\mathrm{A}$ (maternal). b Magnetic resonance brain images of the index patient at the age of 16 years in T1-weighted contrast-enhanced sagittal (sag) and coronal (cor) planes as well as T2-weighted transverse view (trans) show cerebellar atrophy with widening of the cerebellar cortical sulci (arrows) and interfolial spaces (arrow heads) a HEXA gene

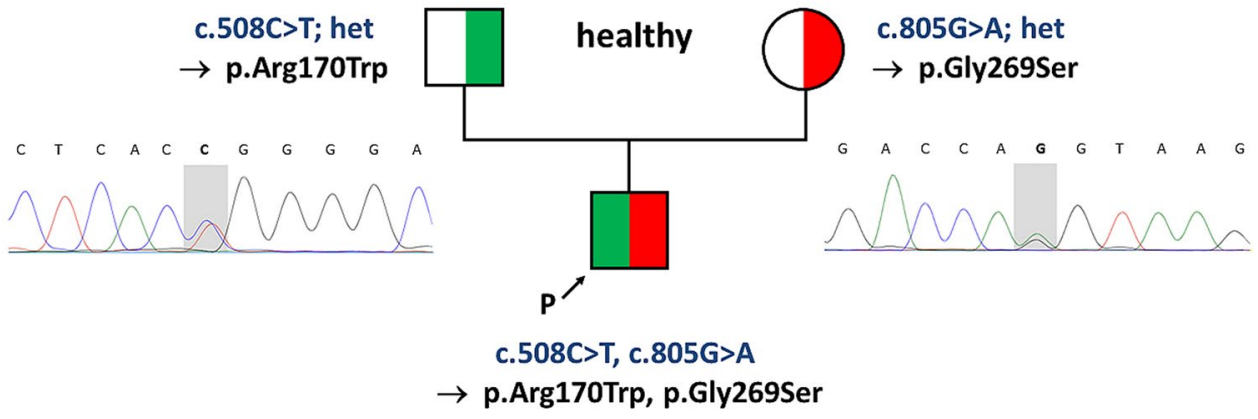

Late-onset Tay-Sachs disease

b

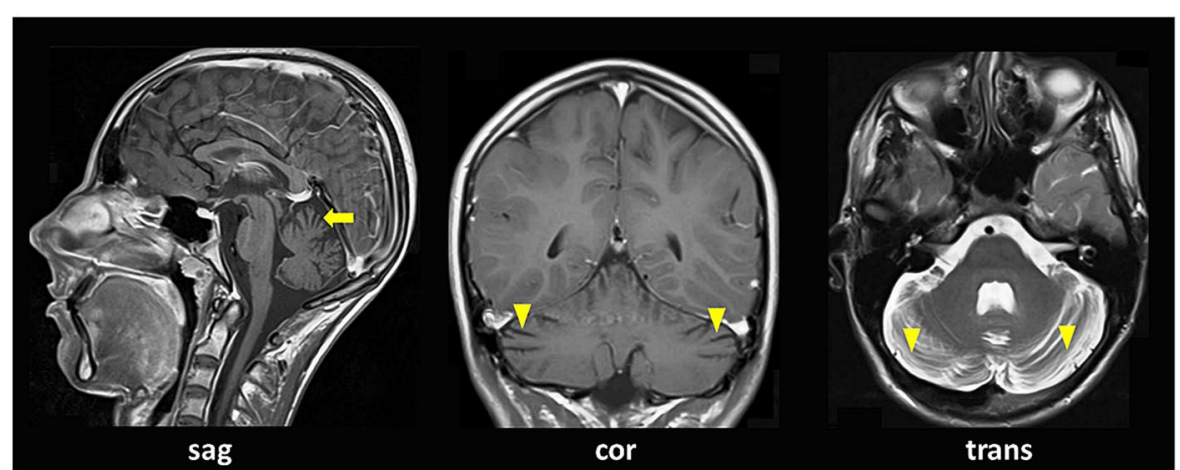

Cattell's Culture Fair Test (CFT20-R) assigned his processing speed, verbal working memory performance, perceptual reasoning, semantic knowledge and general intelligence to the lower limit of the age-adjusted norm.

Tay-Sachs disease (TSD, MIM \#272800) is a rare autosomal recessive progressive neurodegenerative disorder caused by pathogenic variants in HEXA (hexosaminidase A gene, MIM *606869) that impairs $\beta$-hexosaminidase A (HexA) enzyme activity, resulting in lysosomal accumulation of GM2 gangliosides within the central nervous system. The most common severe infantile form leads to early childhood death, owing to lack or negligible enzyme activity [4]. Lateonset forms of TSD result of varying grades of preserved residual enzyme activity manifesting with a chronic clinical course of disease. Progressive degeneration of upper and lower motor neurons with onset before 25 years of age may mimic juvenile amyotrophic lateral sclerosis (JALS) [5].

While the specific combination of the patient's pathogenic variants in HEXA has to our knowledge not yet been described, the first variant c.508C $>\mathrm{T}$ was reported in association with the infantile course of TSD with a complete loss-of-function in in-vitro assays [6]. A detailed characterization of the second variant c. $805 \mathrm{G}>\mathrm{A}$, has recently been described by Jahnova et al. to provoke later-onset forms of disease owing to a residual HexA activity of 1.8-4.1\% [7]. In a systemic Orphanet-survey performed in 2020 the overall birth prevalence of TSD was estimated at 0.28/100,000 [8]. Considering the limited number of patients carrying the c. $805 \mathrm{G}>\mathrm{A}$ variant in $H E X A$ previously published, the presence of this specific variant within a cohort of $14 \mathrm{Czech}$ LOTS patients is astonishing [7]. While a geographical clustering of the variant c. $805 \mathrm{G}>\mathrm{A}$ cannot be ruled out, the numbers suggest that TSD and especially its late-onset form (LOTS) still remain widely under- or misdiagnosed. In the case described here, JALS was initially suspected, because the clinical subacute progression of upper and lower motor neuron compromise fulfilled the revised El Escorial criteria for probable ALS [5]. A comparative analysis results in one indicator that enables a distinction between disease JALS and LOTS, i.e. atrophy of the cerebellum (Table 1). Notably, all 14/14 LOTS patients described by Jahnova et al. as well as all 18/18 LOTS patients reported by Neudorfer et al. exhibit the clinical finding of cerebellar atrophy [4, 7].

LOTS patients may frequently manifest with debilitating neuropsychiatric features and/or cognitive dysfunction. Another recent study revealed that 7/7 LOTS patients, all of whom also exhibited considerable global cerebellar atrophy on MRI, showed evidence of cerebellar cognitive affective syndrome (CCAS) [9]. CCAS has been attributed to affection of the cerebellar posterior lobe and may occur separately or together with cerebellar motor- and vestibular syndrome. As cognitive cerebellar syndrome, it is believed 
Table 1 Differential diagnosis of late-onset Tay-Sachs and juvenile amyotrophic lateral sclerosis compared with the symptoms presented by the index patient

\begin{tabular}{llll}
\hline Symptom & LOTS & JALS & Index patient \\
\hline Age of onset (years) & $10-36$ & $11-19$ & 13 \\
Cachexia & $-l+$ & + & + \\
Dysarthria & + & + & + \\
Muscle weakness & + & + & + \\
Muscle atrophy & + & + & + \\
Muscle fasciculations & + & + & + \\
Hyperreflexia & + & + & + \\
Cerebellar ataxia & + & + & + \\
Cerebellar atrophy & + & - & + \\
Tremor & + & - & + \\
Cognitive impairment & + & - & + \\
Elevated serum CK & $(+)$ & - & + \\
\hline
\end{tabular}

LOTS late-onset Tay-Sachs, JALS juvenile amyotrophic lateral sclerosis

to reflect dysmetria of thought, analogous to dysmetria of motor control, impairing executive, linguistic and visuospatial functions as well as regulation of emotion and affect [10]. CCAS was identified using a newly developed and validated CCAS syndrome scale, specifically designed for the expedited clinical assessment of cognition and neuropsychiatric features in patients with cerebellar disorders [11].

Accurate and early diagnosis is becoming increasingly relevant with new treatment options emerging. Investigations of various therapeutic strategies have shown encouraging results and motivated their advancement to clinical trials. Currently active interventional studies listed in the ClinicalTrials.gov database include hematopoietic stem cell transplantation (Enriched hematopoetic stem cell infusion: phase 1/2, USA, NCT01372228), enzyme replacement therapy, substrate reduction therapy (Miglustat: phase 3, Iran, NCT03822013; Venglustat: phase 3, USA, NCT04221451; Miglustat and ketogenic diet: phase 4, USA, NCT02030015), umbilical cord blood (UBC) transplantation (UBC-derived oligodendrocyte-like cells, phase 1, USA, NCT02254863), cerebellar ataxia treatment (N-Acetyl-L-Leucine: phase 2, USA, NCT03759665) and gene therapy (AXO-AAV-GM2: phase 1, USA, NCT04669535).

Since diagnosis identification is the first, yet decisive prerequisite for the advancement of an effective therapy, emphasis on the clinical findings of atrophy and compromise of the cerebellum in LOTS diagnostic guidelines may facilitate diagnosis.

Acknowledgements We thank the patient and his family for their contribution and consent regarding publication of their data. We acknowledge valuable expert advice of Prof. Dr. Christoph Hübner. V.T. is recipient of a MeDDrive grant of the Medical Faculty, TU Dresden.

Funding Open Access funding enabled and organized by Projekt DEAL.

\section{Declarations}

Conflicts of interest The authors declare no conflict of interest.

Ethical approval All procedures were in accordance with the Declaration of Helsinki (1964) and its later amendments.

Informed consent The subjects of this study provided written informed consent to publish the data reported in the article for scientific purposes.

Open Access This article is licensed under a Creative Commons Attribution 4.0 International License, which permits use, sharing, adaptation, distribution and reproduction in any medium or format, as long as you give appropriate credit to the original author(s) and the source, provide a link to the Creative Commons licence, and indicate if changes were made. The images or other third party material in this article are included in the article's Creative Commons licence, unless indicated otherwise in a credit line to the material. If material is not included in the article's Creative Commons licence and your intended use is not permitted by statutory regulation or exceeds the permitted use, you will need to obtain permission directly from the copyright holder. To view a copy of this licence, visit http://creativecommons.org/licenses/by/4.0/.

\section{References}

1. Holtgrewe M, Stolpe O, Nieminen M, Mundlos S, Knaus A, Kornak U, Seelow D, Segebrecht L, Spielmann M, FischerZirnsak B, Boschann F, Scholl U, Ehmke N, Beule D (2020) VarFish: comprehensive DNA variant analysis for diagnostics and research. Nucleic Acids Res 48(W1):W162-W169. https:// doi.org/10.1093/nar/gkaa241

2. Köhler S, Gargano M, Matentzoglu N, Carmody LC, LewisSmith D, Vasilevsky NA, Danis D, Balagura G, Baynam G, Brower AM, Callahan TJ, Chute CG, Est JL, Galer PD, Ganesan S, Griese M, Haimel M, Pazmandi J, Hanauer M, Harris NL, Hartnett MJ, Hastreiter M, Hauck F, He Y, Jeske T, Kearney H, Kindle G, Klein C, Knoflach K, Krause R, Lagorce D, McMurry JA, Miller JA, Munoz-Torres MC, Peters RL, Rapp CK, Rath AM, Rind SA, Rosenberg AZ, Segal MM, Seidel MG, Smedley D, Talmy T, Thomas Y, Wiafe SA, Xian J, Yüksel Z, Helbig I, Mungall CJ, Haendel MA, Robinson PN (2021) The human phenotype ontology in 2021. Nucleic Acids Res 49(D1):D1207D1217. https://doi.org/10.1093/nar/gkaa1043

3. Richards S, Aziz N, Bale S, Bick D, Das S, Gastier-Foster J, Grody WW, Hegde M, Lyon E, Spector E, Voelkerding K, Rehm HL (2015) ACMG Laboratory Quality Assurance Committee Standards and guidelines for the interpretation of sequence variants: a joint consensus recommendation of the American College of Medical Genetics and Genomics and the Association for Molecular Pathology. Genet Med 17:405-424. https://doi. org/10.1038/gim.2015.30

4. Neudorfer O, Pastores GM, Zeng BJ, Gianutsos J, Zaroff CM, Kolodny EH (2005) Late-onset Tay-Sachs disease: phenotypic 
characterization and genotypic correlations in 21 affected patients. Genet Med 7:119-123. https://doi.org/10.1097/01. gim.0000154300.84107.75

5. Brooks BR, Miller RG, Swash M, Munsat TL, World Federation of Neurology Research Group on Motor Neuron Diseases (2000) El Escorial revisited: revised criteria for the diagnosis of amyotrophic lateral sclerosis. Amyotroph Lateral Scler Other Motor Neuron Disord 1:293-299. https://doi.org/10.1080/14660 8200300079536

6. Martin DC, Mark BL, Triggs-Raine BL, Natowicz MR (2007) Evaluation of the risk for Tay-Sachs disease in individuals of French Canadian ancestry living in new England. Clin Chem 53:392-398. https://doi.org/10.1373/clinchem.2006.082727

7. Jahnová $H$, Poupětová $H$, Jirečková J, Vlášková $H$, Koštálová E, Mazanec R, Zumrová A, Mečirr P, Mušová Z, Magner M (2019) Amyotrophy, cerebellar impairment and psychiatric disease are the main symptoms in a cohort of 14 Czech patients with the late-onset form of Tay-Sachs disease. J Neurol 266:1953-1959. https://doi.org/10.1007/s00415-019-09364-3

8. Orphanet Report Series, Rare Diseases collection (2020) Number 1: https://www.orpha.net/orphacom/cahiers/docs/GB/Preva lence_of_rare_diseases_by_alphabetical_list.pdf Accessed 27 Jan 2021

9. Stephen CD, Balkwill D, James P, Haxton E, Sassower K, Schmahmann JD, Eichler F, Lewis R (2020) Quantitative oculomotor and nonmotor assessments in late-onset GM2 gangliosidosis. Neurology 94(7):e705-e717. https://doi.org/10.1212/ WNL.0000000000008959

10. Schmahmann JD, Sherman JC (1998) The cerebellar cognitive affective syndrome. Brain 121:561-579. https://doi.org/10.1093/ brain/121.4.561

11. Hoche F, Guell X, Vangel MG, Sherman JC, Schmahmann JD (2018) The cerebellar cognitive affective/Schmahmann syndrome scale. Brain 141:248-270. https://doi.org/10.1093/brain/awx317 